\title{
Will climate change be beneficial or detrimental to the invasive swede midge in North America? Contrasting predictions using climate projections from different general circulation models
}

\author{
ANNA M. MIKA*, ROSS M. WEISS $\dagger$, OWEN OLFERT $\dagger$, REBECCA H. HALLETT*and \\ JONATHAN A. NEWMAN* \\ *Department of Environmental Biology, University of Guelph, Guelph, ON, Canada N1G 2 W1, $\dagger$ Agriculture and Agri-Food Canada, \\ Saskatoon Research Centre, 107 Science Place, Saskatoon, Canada S7N 0X2
}

\begin{abstract}
Climate change may dramatically affect the distribution and abundance of organisms. With the world's population size expected to increase significantly during the next 100 years, we need to know how climate change might impact our food production systems. In particular, we need estimates of how future climate might alter the distribution of agricultural pests. We used the climate projections from two general circulation models (GCMs) of global climate, the Canadian Centre for Climate Modelling and Analysis GCM (CGCM2) and the Hadley Centre model (HadCM3), for the A2 and B2 scenarios from the Special Report on Emissions Scenarios in conjunction with a previously published bioclimatic envelope model (BEM) to predict the potential changes in distribution and abundance of the swede midge, Contarinia nasturtii, in North America. The BEM in conjunction with either GCM predicted that $C$. nasturtii would spread from its current initial invasion in southern Ontario and northwestern New York State into the Canadian prairies, northern Canada, and midwestern United States, but the magnitude of risk depended strongly on the GCM and the scenario used. When the CGCM2 projections were used, the BEM predicted an extensive shift in the location of the midges' climatic envelope through most of Ontario, Quebec, and the maritime and prairie provinces by the 2080s. In the United States, $C$. nasturtii was predicted to spread to all the Great Lake states, into midwestern states as far south as Colorado, and west into Washington State. When the HadCM3 was applied, southern Ontario, Saskatchewan, and Washington State were not as favourable for $C$. nasturtii by the 2080s. Indeed, when used with the HadCM3 climate projections, the BEM predicted the virtual disappearance of 'very favourable' regions for $C$. nasturtii. The CGCM2 projections generally caused the $B E M$ to predict a small increase in the mean number of midge generations throughout the course of the century, whereas, the HadCM3 projections resulted in roughly the same mean number of generations but decreased variance. Predictions of the likely potential of $C$. nasturtii spatial spread are thus strongly dependent on the source of climate projections. This study illustrates the importance of using multiple GCMs in combination with multiple scenarios when studying the potential for spatial spread of an organism in response to climate change.
\end{abstract}

Keywords: agricultural pest, bioclimatic envelope model, climate change, CLIMEX, elevated temperature, global warming, precipitation

Received 9 July 2007; revised version received 24 January 2008 and accepted 1 February 2008

Correspondence: Jonathan A. Newman, e-mail:

jnewma01@uoguelph.ca

(C) 2008 The Authors

Journal compilation (C) 2008 Blackwell Publishing Ltd 


\section{Introduction}

Climate change has the potential to affect species distribution and habitat composition (Pearson et al., 2002). Species will differ in their response to climate change depending on their environmental niche properties (Thuiller et al., 2005) and physiological characteristics (Beaumont \& Hughes, 2002). Some will adapt to the changes, some will move, and some will go extinct. Insects in particular are likely to be affected by climate change because they are ectothermic and are sensitive to precipitation (Bale et al., 2002). Small fluctuations in climate variables, such as temperature and precipitation, could dramatically influence their metabolic function, rates of consumption and development, migration, voltinism, larval emergence and survival (Beaumont \& Hughes, 2002), and hence their geographic distribution.

Many insects are also highly mobile and may, therefore, respond to climate change by shifting their spatial distribution. Such changes have been convincingly documented for butterflies in Britain, Australia, and North America (Dennis \& Hardy, 1999; Hill et al., 1999; Beaumont \& Hughes, 2002; Oberhauser \& Peterson, 2003; Crozier \& Dwyer, 2006), ground beetles (Eyre et al., 2004), cicadas species (Robertson et al., 2004), tsetse flies (Terblanche et al., 2006), and ticks (Wilkinson, 1967; Lindgren et al., 2000; Estrada-Pena, 2002). Analyses of how agricultural pest insects will respond to climate change are surprisingly rare (but see Coviella \& Trumble, 1999; McKenney et al., 2003; Gevrey \& Worner, 2006).

Swede midge, Contarinia nasturtii (Diptera: Cecidomyiidae), is a pest on plants of the Brassicaceae, which include canola, cabbage, broccoli, cauliflower, and Brussels sprouts. It has also been found on nonagricultural Brassicaceae including Isatis tinctoria (woad), Rapistrum rugosum (annual bastard-cabbage), Rorippa spp. hybrid, Sisymbrium officinale (hedgemustard or hedgeweed) (Stokes, 1953).

C. nasturtii is endemic to Europe and Southeast Asia, but has been observed in North America since 1996 (Hallett \& Heal, 2001). Adults overwinter in the soil and emerge in May to mate. The larvae feed on the plant, causing it to be misshapen or have galls on leaves, petioles, and flower buds. C. nasturtii has two to five generations per year depending on temperature and soil moisture conditions. Modelling has shown that this pest has the potential to become established in North America, with the Great Lakes region being one of the areas at greatest risk (Olfert et al., 2006).

Olfert et al. (2006) used data on C. nasturtii's distribution in Eurasia to construct a bioclimatic envelope model (BEM) using CLIMEX 2.0 (Sutherst et al., 2004). They then applied their BEM to Canada to investigate the potential risk of $C$. nasturtii's spatial spread. Their model has proven to be useful as southern Ontario and Quebec have been invaded by C. nasturtii (Canadian Food Inspection Agency, 2007). Recent detections of adults have also been made in the fields in Saskatchewan and Nova Scotia (M. P. Mignault, personal communication). In the United States, C. nasturtii has been observed in 25 New York counties and locations in Massachusetts and New Jersey (United States Department of Agriculture, 2007; A. M. Shelton, personal communication) as predicted by the model. In the current study, we set out to predict how climate change may shift the bioclimatic envelope of this species, and to examine how this shift might alter the pattern of potential risk for the spatial spread of this important crop pest.

Model-based studies of climate change impacts on species distributions vary in the sophistication with which they treat climate change. The simplest approach is to apply a constant (in space and time) change to the temperature (e.g. $+2{ }^{\circ} \mathrm{C}$; Sutherst et al., 2000; Newman, 2004; Olfert et al., 2004). This approach is easily implemented (e.g. CLIMEX provides a 'climate change' option, applied as a uniform increment increase in temperature), it eases the difficulty of interpretation, and it corresponds well with the public's notion of a global average increase in temperature. However, biologically, the global average increase in temperature is a meaningless figure. No ecosystem will experience this increase; rather, climate variables will vary both spatially and temporally (both seasonally and on longer time scales).

More sophisticated treatments of climate in such model-based studies utilize the projections from general circulation models (GCMs) (e.g. Newman, 2005, 2006). Forty-five of the sixty-five most recent BEM studies used GCM projections to account for future climate. According to the Intergovernmental Panel on Climate Change (IPCC, 2001), as of the third assessment report (IPCC, 2007), there were 15 climate modelling centres around the world which together had developed some 31 coupled atmosphere-ocean GCMs, and several regional climate models. These models are used with four families of standard scenarios of future greenhouse gas emissions detailed in the Special Report on Emissions Scenarios (SRES), which are based on demographic, politico-societal, economic, and technological changes from the present (Nakicenovic et al., 2000). This amounts to over 40 individual scenarios (Nakicenovic et al., 2000) and hundreds of model-scenario combinations. Although there is some degree of agreement in the projections of all of these models, this agreement may be quite coarse from an ecological perspective. Therefore, as $\mathrm{Xu} \&$ Yan (2001) have pointed out, the use of projections from different climate models may 
not lead to robust predictions from BEMs. Nevertheless, of the 65 BEM studies conducted since 1994 (62 of which have been since 2000$)$, only $14(21.5 \%)$ use projections from more than one GCM, and only $10(15.4 \%)$ of these compare the results using multiple GCMs in conjunction with multiple climate change scenarios. A few studies (Thuiller, 2004; del Barrio et al., 2006; Harrison et al., 2006) have been based on more than one GCM and one scenario, but did not use a factorial design. In this paper, we present bioclimatic envelope predictions for C. nasturtii based on two different GCMs and two different SRES scenarios.

\section{Methods}

\section{Climate variables}

Climate change projections were obtained from the IPCC data distribution site (IPCC, 2002) as monthly means for two GCMs: the Canadian Centre for Climate Modelling and Analysis CGCM2 model, and Hadley Centre HadCM3 model. For each GCM, we used the SRES A2 and B2 scenarios because projections for both scenarios were available from both GCMs. The A2 scenario represents high human population growth and slow technological advancement while the B2 scenario has moderate population growth with more environmental protection (Nakicenovic et al., 2000). These two scenarios are sometimes described as the 'mediumhigh' and 'medium-low' emissions scenarios, as they are expected to result in $\mathrm{CO}_{2}$ concentrations of 840 and $620 \mathrm{ppm}$ by the year 2100 , respectively (for comparison, the A1FI 'high emissions' and the B1 'low emissions' scenarios result in concentrations of 960 and $550 \mathrm{ppm}$ respectively).

Maximum temperature $\left(T_{\max }\right)$, minimum temperature $\left(T_{\mathrm{min}}\right)$, precipitation, and relative humidity $(\mathrm{RH} \%)$ were readily available for the HadCM3 model. Relative humidity was derived for the CGCM2 model using the following formula:

$$
\mathrm{RH}(\%)=100 \times \frac{\mathrm{e}_{\mathrm{a}}}{\mathrm{e}^{0}(T)} .
$$

Equation (1) represents the ratio of the actual $\left(e_{a}\right)$ to the saturation $\left[\mathrm{e}^{0}(T)\right]$ vapour pressure at the same temperature $(T)$. The Food and Agriculture Organization of the United Nations (Allen et al., 1998) suggests this approximation for $\mathrm{RH} \%$. This estimate may not be accurate for arid areas (Allen et al., 1998), but because our study focused mainly on nonarid regions of North America, we considered that Eqn (1) provided a reasonable estimate of $\mathrm{RH} \%$. (We provide evidence in Fig. 4 and in 'Discussion' that the BEM predictions are very sensitive to $\mathrm{RH} \%$, but insensitive to the method of calcula- tion for $\mathrm{RH} \%$ ). The dewpoint temperature was estimated using $T_{\min }$ in the calculation of $\mathrm{e}_{\mathrm{a}}$ and $T_{\max }$ was used as the temperature in $\mathrm{e}^{0}$. The BEM requires $\mathrm{RH} \%$ at 09:00 and 15:00 hours. The RH\% calculated using Eqn (1) was used as the RH\% at 15:00 hours, and the RH\% at 09:00 hours was calculated by dividing $\mathrm{RH} \%$ at $15: 00$ hours by 0.85 (the reverse calculation is performed by CLIMEX when RH\% at 09:00 hours is provided, but $\mathrm{RH} \%$ at 15:00 hours is missing). For the HadCM3 projections, the downloaded $\mathrm{RH} \%$ projections were used as the 15:00 hours values and the $\mathrm{RH} \%$ at 09:00 hours derived the same way as for CGCM2. Because a value of over $100 \%$ could be achieved using this method, a maximum value of $100 \%$ was set for $\mathrm{RH} \%$ at 09:00 hours.

The model results were evaluated using the 30 year averages for the four standard IPCC time slices: the baseline period (1961-1990), the 2020s (2010-2039), the 2050s (2040-2069), and the 2080s (2070-2099).

\section{CLIMEX}

CLIMEX (Hearne Scientific Software, Australia) is a commonly used (>100 studies) computer modelling program that uses the observed distribution and abundance data of a species to estimate its optimal climate and climate tolerance limits to model its potential distribution (Sutherst et al., 2000). The software uses growth and stress (heat, cold, wet, dry) indices to predict how the species will react to climate in different regions of the world (Sutherst et al., 2000). CLIMEX derives Ecoclimatic Index values (EI) that describe the suitability of specific locations for species survival and reproduction. The parameters include temperature (TI), diapause (DI), light (LI), moisture (MI), heat stress (HS), cold stress (CS), wet stress (WS), and dry stress (DS). The EI values are obtained by combining a Growth Index (GI) with stress indices (dry, wet, cold, and hot) that describe conditions unfavourable for growth.

For this study, the parameter values determined by Olfert et al. (2006) were used (Table 1). See Olfert et al. (2006) for a complete discussion of model development, sensitivity, and validity. In brief, in accordance with previous observations (Readshaw, 1961), Olfert et al. (2006) found that temperature and soil moisture are the most important variables affecting $C$. nasturtii's distribution, growth, and control. Their model was fit to reflect this information and resulted in a realistic representation of the insect's current distribution and phenology in Europe (Olfert et al., 2006).

Olfert et al. (2006) validated their BEM by comparing the model's resulting distribution with empirical observations of $C$. nasturtii for eastern Europe from five different sources of distribution data. They also 
Table 1 CLIMEX parameter values for the bioclimatic envelope model of the swede midge (Olfert et al., 2006), Contarinia nasturtii

\begin{tabular}{|c|c|c|c|}
\hline Index & Parameter & Description & Value \\
\hline \multirow[t]{4}{*}{ Temperature } & DVO & Limiting low temperature & $10.0^{\circ} \mathrm{C}$ \\
\hline & DV1 & Lower optimal temperature & $16.0^{\circ} \mathrm{C}$ \\
\hline & DV2 & Upper optimal temperature & $25.0^{\circ} \mathrm{C}$ \\
\hline & DV3 & Limiting high temperature & $32.5^{\circ} \mathrm{C}$ \\
\hline \multirow[t]{4}{*}{ Moisture } & SM0 & Limiting low soil moisture & 0.15 \\
\hline & SM1 & Lower optimal soil moisture & 0.40 \\
\hline & SM2 & Upper optimal soil moisture & 1.40 \\
\hline & SM3 & Limiting high soil moisture & 1.50 \\
\hline \multirow[t]{5}{*}{ Diapause } & DPD0 & Diapause induction day length & $14 \mathrm{~h}$ \\
\hline & DPT0 & Diapause induction temperature & $10.0^{\circ} \mathrm{C}$ \\
\hline & DPT1 & Diapause termination temperature & $6.0^{\circ} \mathrm{C}$ \\
\hline & DPD & Diapause development days & 150 \\
\hline & DPSW & Diapause indicator for winter diapause & 0 \\
\hline \multirow[t]{2}{*}{ Cold stress } & TTCS & Cold stress temperature threshold & $-18.0^{\circ} \mathrm{C}$ \\
\hline & THCS & Cold stress temperature rate & -0.0008 \\
\hline \multirow[t]{2}{*}{ Heat stress } & TTHS & Heat stress temperature threshold & $35.0^{\circ} \mathrm{C}$ \\
\hline & THHS & Heat stress temperature rate & 0.005 \\
\hline \multirow[t]{2}{*}{ Dry stress } & SMDS & Dry stress threshold & 0.10 \\
\hline & HDS & Dry stress rate & -0.01 \\
\hline \multirow[t]{2}{*}{ Wet stress } & SMWS & Wet stress threshold & 1.50 \\
\hline & HWS & Wet stress rate & 0.0005 \\
\hline \multirow[t]{2}{*}{ Day-degree accumulation above DV0 } & DV0 & & 10 \\
\hline & DV3 & & $32.5^{\circ} \mathrm{C}$ \\
\hline \multirow[t]{2}{*}{ Day-degree accumulation above DV3 } & DV3 & & $32.5^{\circ} \mathrm{C}$ \\
\hline & DV4 & & 100 \\
\hline \multirow[t]{2}{*}{ Day-degree accumulation above DVCS } & DVCS & & 6.50 \\
\hline & DV4 & & 100 \\
\hline Degree-days per generation & PDD & Minimum degree days above DV0 to complete generation & 200 \\
\hline
\end{tabular}

compared the seasonal phenology and number of generations to the several accounts of published data from Europe. Finally, model results relating to phenology using southern Ontario weather data were compared to collected field data.

Following Olfert et al. (2006), we categorized CLIMEX's EI output into 'unfavourable' (0-10), 'suitable' (10-20), 'favourable' (20-30), and 'very favourable' (>30). Olfert et al. (2006) found that temperature and, particularly, soil moisture where the primary variables determining C. nasturtii range and abundance. CLIMEX estimates the number of generations solely based on the total number of degree-days above the lower temperature threshold for population growth (Sutherst et al., 2004). This method results in biologically unrealistic results at this spatial scale. We therefore estimated the number of generations using the EI values as follows:

$$
\text { Generations }=V_{\mathrm{m}}\left(\frac{\mathrm{EI}-10}{\mathrm{EI}-10+K_{\mathrm{h}}}\right) .
$$

We found Eqn (2) to be a much better approximation to the weather station data for the current distribution of voltinism than that produced by CLIMEX (results not shown).

In Eqn (2), we used $V_{\mathrm{m}}=10, K_{\mathrm{h}}=25$ as the values for the constants, which resulted in five generations occurring in areas classified as $\mathrm{EI}=35$; five is the maximum number of generations currently observed in nature (Olfert et al., 2006). Note, the number of possible generations in Eqn (2) is six for $\mathrm{EI}=47.5$, which may be achievable in the future. Equation (2) also ensures that the number of generations is zero for $\mathrm{EI} \leq 10$, which was regarded as an area where the species is not likely to establish, although it may occur there.

We used the Geographic Information System ARCGIS version 9.1 (ESRI, Canada) with inverse distance weighting interpolation (ESRI, 2005) to create risk maps.

\section{Results}

\section{Changes in area that have suitable climate}

The EI predictions made using the climate change baseline period (1961-1990) projections (Fig. 1) were 

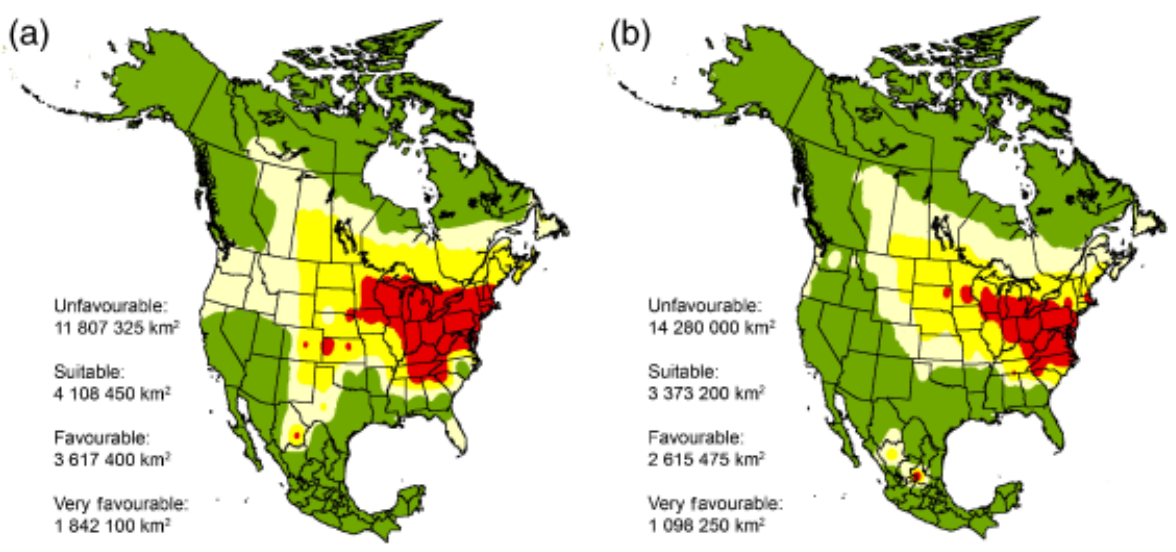

Fig. 1 Ecoclimatic index (EI) for Contarinia nasturtii in North America using the (a) CGCM2 and (b) HadCM3 baseline period (1961-90). Green: 'unfavourable' (<10), light yellow: 'suitable' (10-20), yellow: 'favourable' (20-30), and red: 'very favourable' climate (>30).

similar to those obtained by Olfert et al. (2006) who used climate normals from a $0.5^{\circ}$ world grid dataset (New et al., 1999). Using the baseline projections, C. nasturtii's bioclimatic envelope extends north and west of its current North American distribution in southern Ontario and northern New York.

Although the effects of climate change on the general shifts in the bioclimatic envelope of $C$. nasturtii were similar across scenarios, they differed strongly between the GCMs used, particularly for the regions classified as 'very favourable' (Figs 2 and 3). Based on climate projections from the CGCM2, the region of the bioclimatic envelope classified as 'very favourable' increases in area, moving northward and westward as time passes (Fig. 2). With the climate projections for the HadCM3, this same region contracts as time progresses. The main differences observed are between GCMs rather than between scenarios (although differences between scenarios do begin to emerge by the 2080s; Fig. 3).

In general, climate projections from the CGCM2 lead to predictions of increased areas of climatically 'favourable' and 'very favourable' habitat, and these increases are larger with higher emissions (Fig. 3; compare A2 with B2). The HadCM3 climate projections resulted in predictions of increased areas of climatically 'favourable' habitat, but to large decreases in areas of 'very favourable' climate (Fig. 3). In this case, higher emissions lead to increased areas classified as climatically 'suitable' or 'favourable' by the 2080s, but a decrease in the area classified as climatically 'very favourable'.

\section{Climate factors affecting distribution}

By running the BEM but changing only temperature, precipitation or $\mathrm{RH} \%$ from the baseline period, we were able to determine the relative importance of each climate factor in terms of the observed differences seen in Figs 2 and 3. It is clear from Fig. 4 that the most important driving variables are precipitation and relative humidity, which have almost an identical and substitutable effect. Changing the precipitation or $\mathrm{RH} \%$ had a much larger effect on the location of the bioclimatic envelope than altering the temperature values. This is not surprising because $C$. nasturtii is known to be sensitive to soil moisture (Readshaw, 1966). While precipitation and $\mathrm{RH} \%$ are roughly substitutable, temperature and precipitation (or $\mathrm{RH} \%$ ) have an almost additive effect on the distribution of $C$. nasturtii, with little interaction between the variables (see Fig. 4).

\section{Soil moisture is the most important driving variable}

Olfert et al. (2006) showed that soil moisture is one of the most important driving variables in determining the potential distribution of $C$. nasturtii. It is a key factor in the termination of diapause (Readshaw, 1966) and thus, adult emergence. We confirmed this conclusion in 'Climate factors affecting distribution' (see Fig. 4) showing that temperature contributes little to the predicted location of the bioclimatic envelope of $C$. nasturtii, whereas either precipitation or $\mathrm{RH} \%$ account for nearly all the variability in the distribution and are substitutable.

Because the emergence of $C$. nasturtii is primarily related to soil moisture (Readshaw, 1966), we wanted to be sure that the large differences in predicted swede midge bioclimatic envelopes based on the two GCMs (Figs 2-4, 6), were not simply due to differences in the methods of calculation for the RH\% values. To do this, we used Eqn (1) to generate $\mathrm{RH} \%$ estimates for the HadCM3 and re-ran the BEM using the new values for 

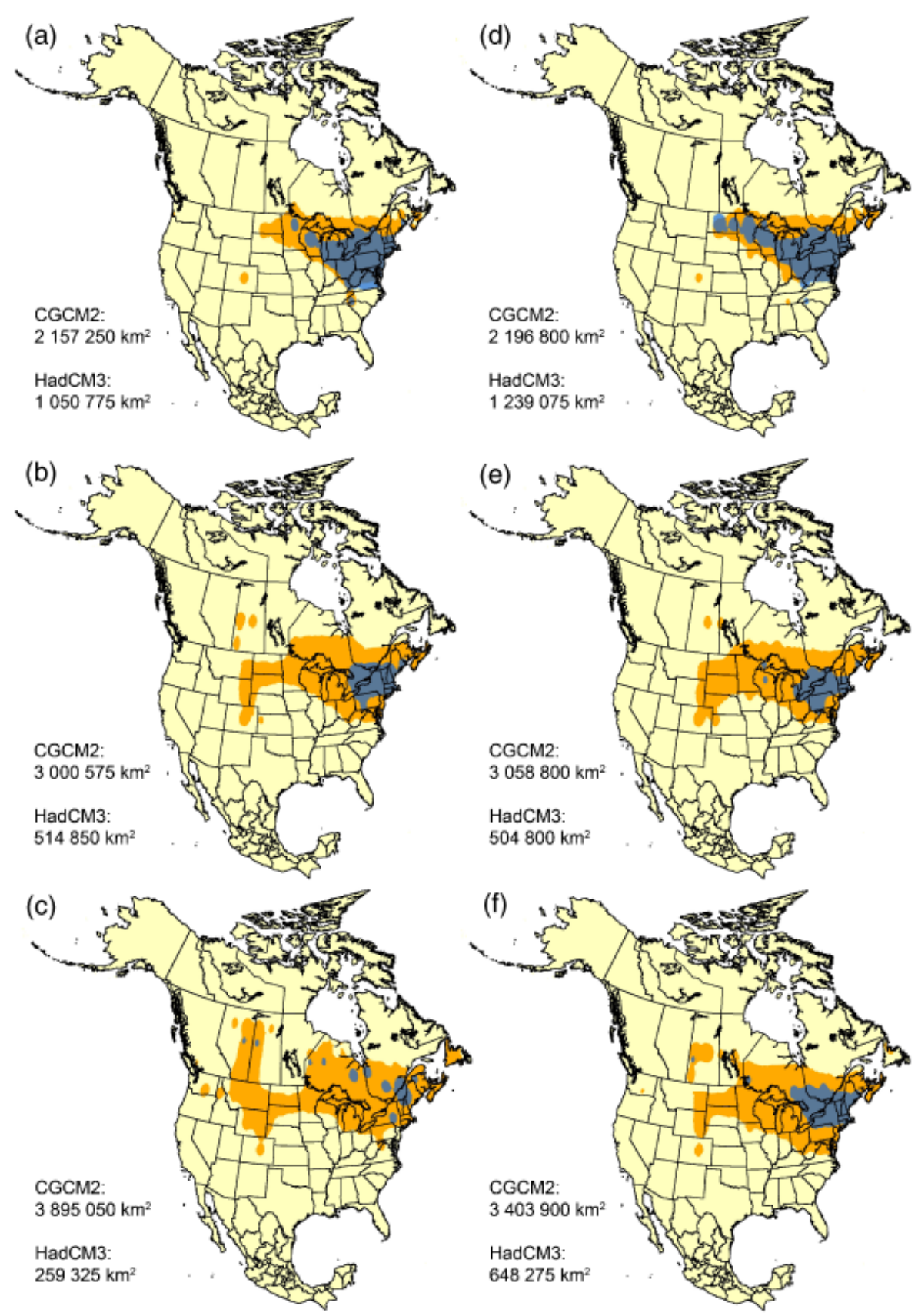

Fig. 2 Shift of the bioclimatic envelope classified as very favourable climate (EI >30) for Contarinia nasturtii for the A2 scenario (a) 2020s, (b) 2050s, (c) 2080s, and B2 scenario (d) 2020s, (e) 2050s, and (f) 2080s. CGCM2 is shown in gold; HadCM3 is shown in blue.

$\mathrm{RH} \%$. The results, which are not shown for brevity, were nearly identical to those presented in Fig. 2. The differences between the GCMs are thus, not due to the method of calculating $\mathrm{RH} \%$ per se, but are almost certainly due to the large differences between these two GCMs in their predictions of summer air temperatures, precipitation, and $\mathrm{RH} \%$.

In Fig. 5, we plot the projected $\mathrm{RH} \%$ for the 2080s for both GCMs for the A2 scenario (for brevity, B2 is not shown) for the baseline and 2080s. Similarly, large differences exist between the GCMs for precipitation (results not shown). It is clear from this figure that the CGCM2 is generally 'moister' than the HadCM3. Taken together, Figs 4 and 5 demonstrate that the variability in the predicted bioclimatic envelope is driven by differences in projected $\mathrm{RH} \%$ (and/or precipitation) between the two GCMs. 

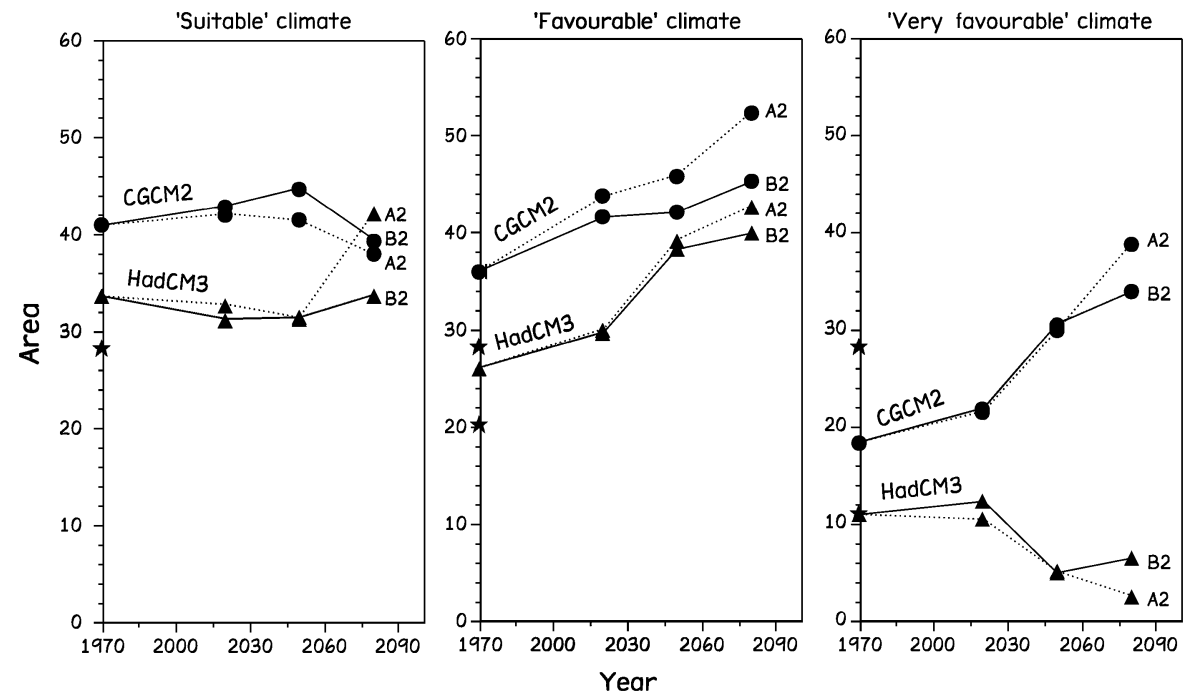

Fig. 3 Changes in the area of the bioclimatic envelope of Contarinia nasturtii. 'Suitable' regions have an Ecoclimatic Index (EI) $=10-20$; $\mathrm{EI}=21-30$ for 'Favourable' regions; and EI $>30$ for 'Very Favourable' Regions. Area is depicted in $\mathrm{km}^{2} \times 10^{5}$. Results generated using the climate projections from the CGCM2 are denoted by circles, results generated using the HadCM3 projections are denoted by triangles, and results generated using the historical climate data provided within CLIMEX are denoted by $\star$. Predictions with the A2 climate change scenario are denoted by dashed lines and solid lines for those with the B2 climate change scenario.

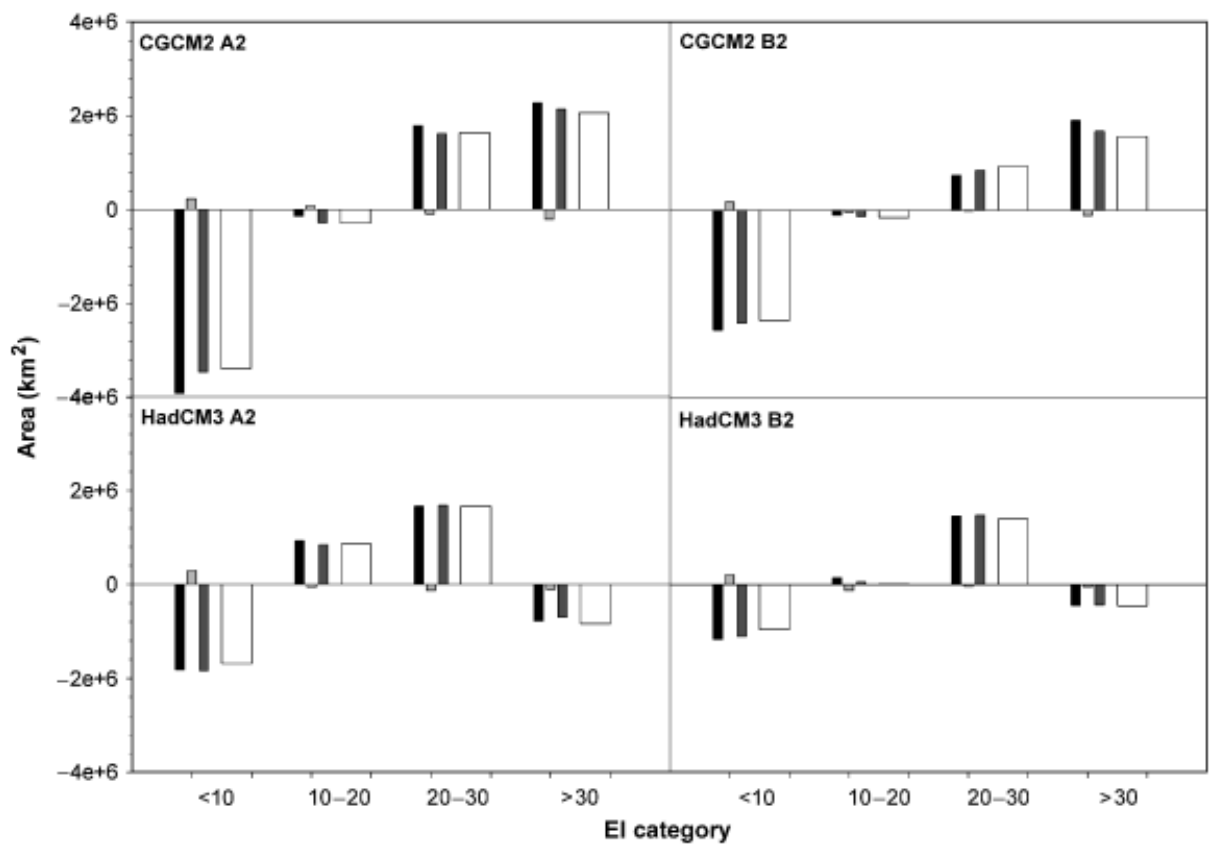

Fig. 4 Change in area of the distribution of Contarinia nasturtii in the 2080s relative to the baseline period (1961-1990) for each category of EI value. For each category of EI, the bars represent, from left to right, the effects of changing only: precipitation, temperature, or relative humidity. Large open bars represent the change relative to the baseline period when all three climate variables are changed simultaneously. We see that changing either precipitation or relative humidity, is sufficient to account for most of the change seen when all three variables are changed. We can also see that precipitation or relative humidity combine roughly additively with temperature to produce the total effect.

\section{Change in the number of generations}

Changes in EI with climate translate into changes in generation time. Again, the major anomalies arise be- tween GCMs, rather than between scenarios with the same GCM. Figure 6 shows the changes in the distribution of voltinism through time. In general, Fig. 6 shows that the number of generations per year could increase

(C) 2008 The Authors

Journal compilation (C) 2008 Blackwell Publishing Ltd, Global Change Biology, 14, 1721-1733 

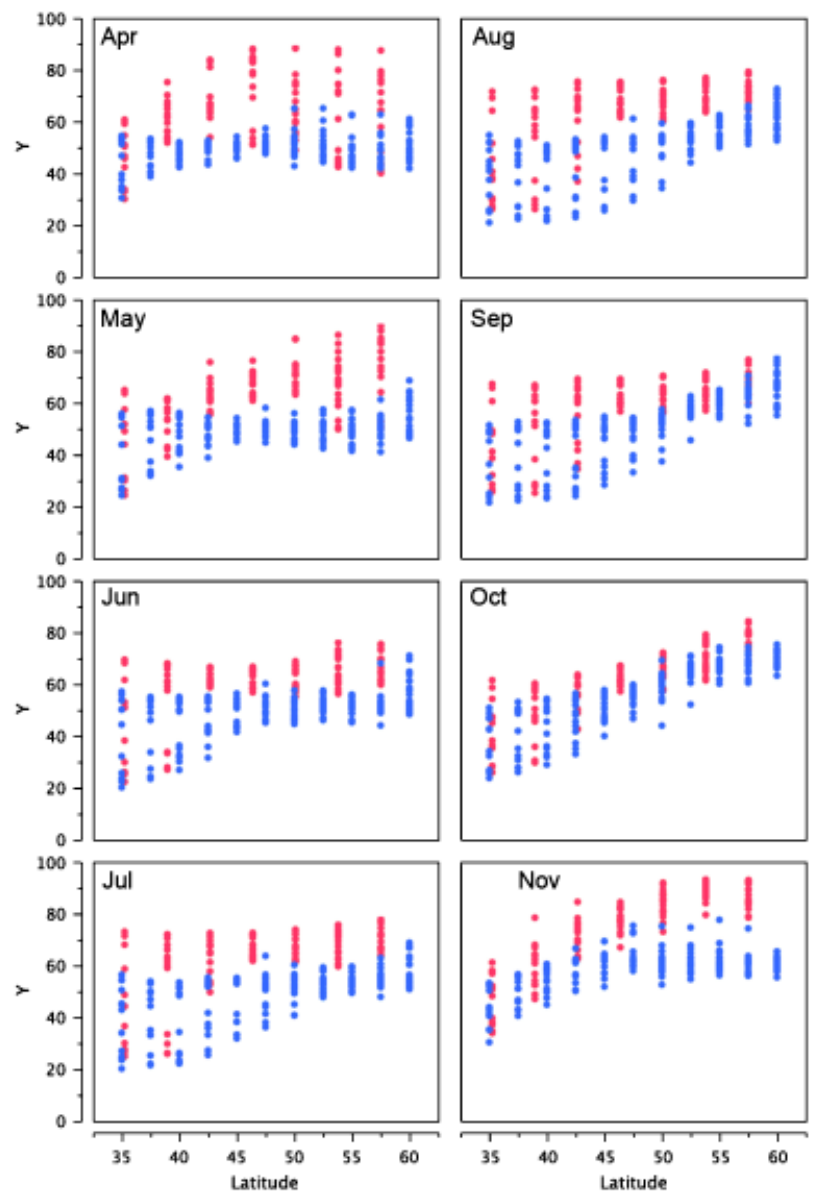
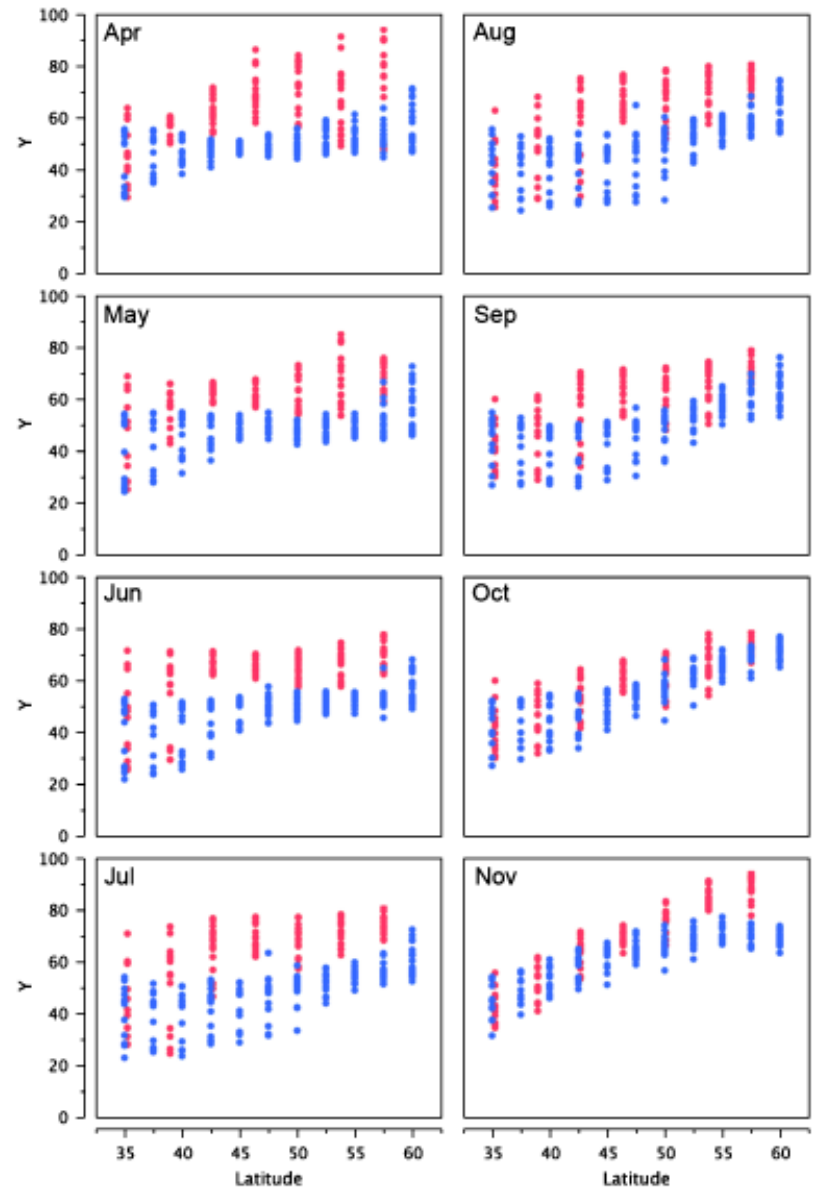

Fig. 5 Total monthly relative humidity (RH\%) in April through November for North American grid cells between $35^{\circ} \mathrm{N}$ and $60^{\circ} \mathrm{N}$ for the 2080s for the A2 scenario (cf Fig. 2). The CGCM2 is shown in red dots while the HadCM3 is shown in blue dots. The graphs on the left represent the RH\% for the baseline period (1961-1990) and the graphs on the right represent those for the 2080s.

using the climate projections from the CGCM2 model, for either scenario. When using the climate projections from the HadCM3 model, the distribution of the number of generations shifts strongly toward fewer generations (i.e. toward the left in Fig. 6).

\section{Discussion}

The limitations of bioclimatic envelope modelling have been thoroughly critiqued and discussed (Pearson \& Dawson, 2003; Hampe, 2004; Segurado \& Araujo, 2004; Pearson et al., 2006). These models can determine which areas have suitable climate for a species to flourish, but cannot predict where they will be found. Because the climate specifications for a species are determined from its current distribution, BEMs generally assume that the species is currently filling its whole niche and that climate is the only determinant of distribution (Beaumont \& Hughes, 2002). However, distribution is also affected by biotic factors such as dispersal limitations, presence of host plants, disturbance, and competition (Gavin \& Hu, 2006) and other abiotic factors such as fire and nutrients (Pearson et al., 2002). For instance, an invasive species (such as C. nasturtii) may not have had enough time to fill its current potential range, especially during initial invasion or when dispersing into patchy habitat islands (Gavin \& Hu, 2006). Furthermore, rare species and species that are on the margin of their distribution tend to be modelled more accurately than species that are in the core of the distribution (Luoto et al., 2005) because if species are limited by climate, then the margin of their distribution most accurately reflects this limitation. Also, scattered dispersed species are modelled less accurately than clumped species and species with high abundance worse than species with low abundance, perhaps because the former may not be occupying their entire tolerable habitat or were not observed due to temporal variations in population densities (Luoto et al., 2005). In the current model, Olfert et al. (2006) developed their BEM based on C. nasturtii's 


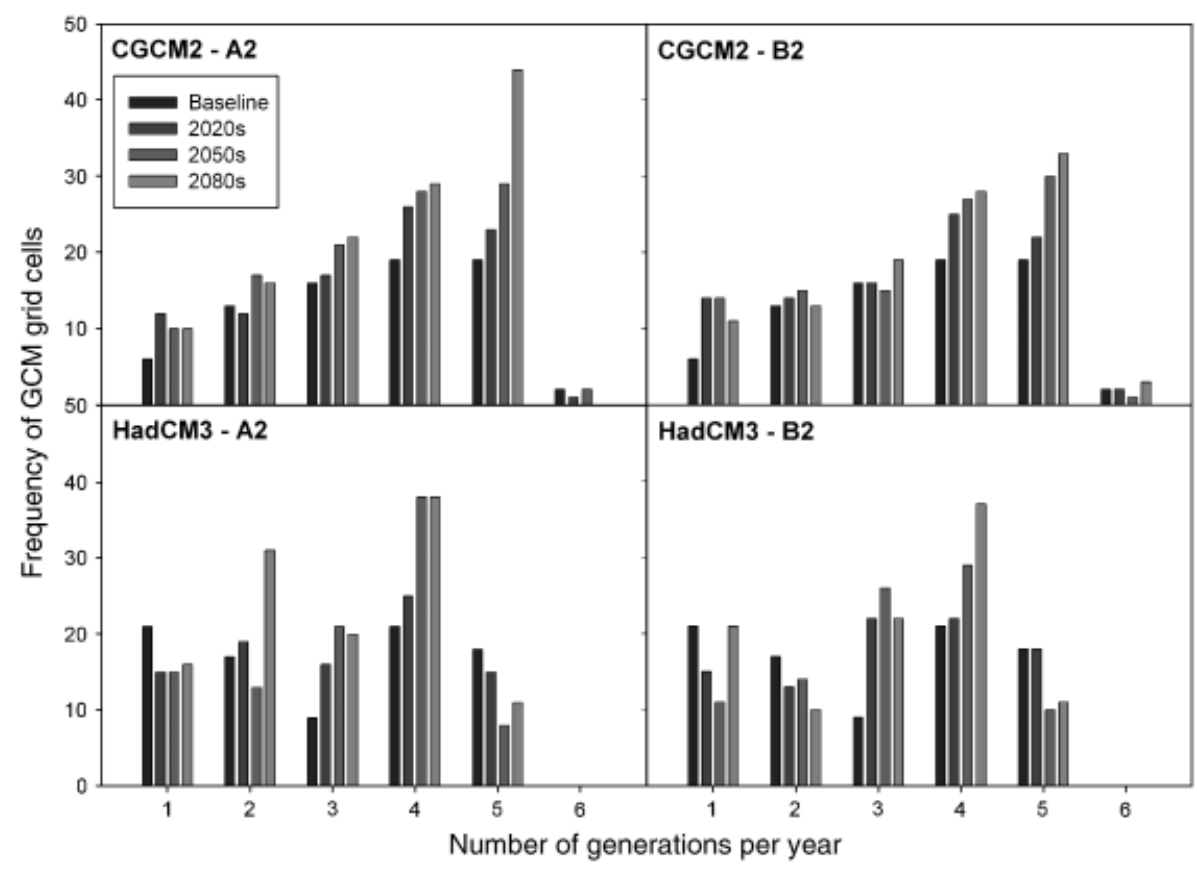

Fig. 6 Frequency of North American grid cells with one or more generations per year for CGCM2 and HadCM3 using the A2 and B2 scenarios. Because of the differences in the spatial resolution of the two GCMS, the total number of grid cells in North America (including ones with no generations per year) is 294 for HadCM3 and 201 for CGCM2.

native (i.e. longstanding) distribution in Eurasia. It is, therefore, reasonable to assume that the model is based on C. nasturtii having filled, and so representing, its entire niche.

Despite these potential drawbacks, BEMs provide valuable insight into the potential future distributions of species, including the identification of species that may be most likely to change and the regions where they may occur based on climatic suitability of an area (Pearson et al., 2002). There are too many species to conduct field and laboratory experiments on all of them in order to determine their potential responses to climate change, and BEMs offer a practical solution for forecasting changes in species distributions (Beaumont \& Hughes, 2002). These models are a useful tool to support risk management efforts for controlling invasive species (McKenney et al., 2003), and can help to narrow down species that future field work should focus on (Beaumont \& Hughes, 2002).

\section{Sources of uncertainty}

When authors make statements to the effect that '15$37 \%$ of species in our sample of regions and taxa will be "committed to extinction"' (Thomas et al., 2004) or 'the distributions of the majority of the 24 [out of 77] butterfly species modeled may decrease in size and latitudinal extent as the intensity of climate change increases' (Beaumont \& Hughes, 2002), readers must appreciate that there is considerable uncertainty associated with such statements. The sources of uncertainty are rarely, if ever, assessed, and to our knowledge no study assesses all of these simultaneously. In this section, we discuss the four sources of uncertainty and the consequences of such uncertainty. First, however, it is worth reminding ourselves of the difference between 'risk' and 'uncertainty'. Risk refers to stochastic events or processes for which the probabilities have been, or can be, estimated. Risk per se holds no special worries for ecologists because when probabilities are known we can provide probability density or probability mass functions that quantify our predictions concerning future ecological states. Uncertainty refers to stochastic events or processes for which the relevant probabilities are either not known, or are perhaps unknowable given current technology.

Perhaps, one of the more significant uncertainties for all models of species responses to climate change is that they do not consider the possibility that the species will adapt to the changing climate. BEMs do not take adaptive evolution into account, but assume that the current climate tolerance limits will continue to restrict the distribution of the species in the future, even with climate change. Apart from micro-organisms, adaptation may be most likely for insects, which often have large populations and short generations, allowing them 
to adapt quickly, perhaps in as little as 80 years. McKenney et al. (2003) suggest that a complete pest risk assessment should include adaptability as well as life cycle, hosts, control options, success of eradication, spread and transport means, in conjunction with current and future bioclimatic envelope locations. Clearly, BEMs cannot accomplish all these objectives, but they can provide a general description of areas that might be at risk of invasion so that precautionary measures can be taken (Pearson et al., 2002). It is very likely that climate change will drive natural selection, but without an explicit genetic model, it is unreasonable to try to incorporate evolution into BEMs.

Climate change scenarios are the next source of uncertainty (IPCC, 2001). There are four families of climate scenarios (Nakicenovic et al., 2000). These scenarios are alternative images of the future, not predictions or forecasts. Because greenhouse gas emissions are the product of complex and poorly understood dynamic systems, driven by mechanisms such as the pace of technological and economic development, long-term emissions predictions are virtually impossible. Unlike the physical models of climate, the scenario models attempt to represent social and political systems that are relatively poorly understood and predictable only with great uncertainty (IPCC, 2001). BEM modellers have clearly accepted that predictions depend on which scenario is used, and have, for quite some time, been using multiple scenarios to make predictions (Beaumont et al., 2007).

Climate models themselves are the third source of uncertainty. The IPCC's fourth assessment report (AR4), released earlier this year lists 23 GCMs from 18 modelling centres (IPCC, 2007). Climatologists have a far deeper mechanistic understanding of climate than can be captured in a mathematical model that will be computationally tractable. Models differ in which processes are captured mechanistically, and which are represented phenomenologically, the number and particular climate feedback mechanisms that operate, horizontal and vertical spatial resolution, and so on. There is no simple way to determine whether one GCM is 'better' than another. Although comparisons between the hindcasts of GCMs and historical data are made (e.g. Bonsal et al., 2003), climate modellers consistently reject such assessments as the sole basis for choosing one model over another. The main reason for this conviction is that there is great uncertainty within each model. There is no guarantee that a model that does well at predicting past climate will do equally well at predicting future climate because we have no historical period during which climate forces have changed in a way analogous to predictions for the very near future. Therefore, the use of multiple models is encouraged for any modelling exercise (Nakicenovic et al., 2000; Newman, 2006).

Notwithstanding this objection, Bonsal et al. (2003) rigorously compared the hindcasts of nine GCMs, including the CGCM2 and HadCM3, for a region of western Canada in terms of how these GCMs corresponded to historical climate data. They demonstrated for that area, that both the Hadley and the Canadian GCMs do an adequate job of modelling the past mean temperature with only minor seasonal differences. However, they reached the conclusion that the HadCM3 precipitation predictions more closely match the historical data than those of the CGCM2 (Bonsal et al., 2003).

Modellers of BEM have been slow to incorporate uncertainty in GCM model structure (see 'Introduction' for details). As mentioned earlier, of the 65 BEM model studies conducted since 1994, only 10 use projections from more than one GCM in conjunction with multiple climate change scenarios. Nearly half of these 65 studies (31) used projections from a Hadley Centre model. Considering the number of GCMs available for biologists' use, previously published BEM studies are heavily biased toward the Hadley Centre models. We wanted to contrast the BEM results derived using the HadCM3 with those obtained when a different, 'less popular' GCM was used. We chose to use the Canadian CGCM2 mainly because all the climate variables required for the CLIMEX model were either available or derivable (RH\%) from the IPCC data centre. This was not true for several other model choices. For example, the GCMs produced by the US Geophysical Fluid Dynamics Lab and the German Max Planck Institute für Meteorologie provide monthly mean temperatures, but not monthly maximum and minimum temperatures (IPCC, 2002) required for the CLIMEX model. Nevertheless, other models also provide the same variables as the CGCM2 (e.g. the Australian CSIRO model and the Japanese CCSR/NIES model) and it remains to be seen whether their projections lead to even more extreme differences in the predictions of BEMs.

Finally, a source of uncertainty little appreciated by ecologists is the within GCM uncertainty. Climate modelling centres routinely generate multiple model versions within a particular model structure, by varying the model parameters within plausible ranges. Sometimes these 'experiments' are presented in isolation, and sometimes they are combined with other 'experiments' to generate so-called perturbed physics ensembles. BEM models rarely distinguish which runs were used to project climate for their particular application.

Finally, we must consider the possibility that these sources of uncertainty interact in some nonadditive way. For example, recently Beaumont et al. (2007) quantitatively compared 13 realizations from three climate 
models (three from CSIRO Mark2 v3.0, four from GISS AOM, and six from MIROC v3.2) for two time periods: current (1985-1995) and future (2025-2035), for predicting bioclimatic envelopes for nine Australian butterflies. For the baseline period (1961-1990), they found that there was more variability of climate projections between GCMs than within an individual GCM. However, projections for the future were more variable both within and between GCMs than for the baseline period. They concluded that internal climate model variability can lead to substantial differences in the extent to which the future distributions of species are projected to change. These can be greater than differences resulting from between-climate model variability' (Beaumont et al., 2007).

Another example of interacting sources of uncertainty is provided by Thuiller (2004). Thuiller conducted an extensive study using multiple BEMs, multiple GCMs, and multiple scenarios. Thuiller's objective was to quantify these sources of uncertainty and to generate a consensus prediction that incorporates this uncertainty into a single predicted bioclimatic envelope. Thuiller's conclusion was that variability induced by the GCMs was small relative to the variability between envelope models. However, it should be noted that although Thuiller compared two GCMs that were run for several scenarios, the two GCMs shared only a single scenario in common (i.e. HadCM3: A1, A2, B1, B2; CSIRO2: A2). Arguably, this limited comparison might miss large differences between other GCMs and/or the same GCMs in other scenarios. Nevertheless, Thuiller's general approach has a great deal of merit and probably deserves wide adoption.

\section{Consequences for agriculture in North America}

For herbivores, their actual distribution, currently and in the future, will depend not just upon the spatial location of their bioclimatic envelope, but also whether the bioclimatic envelope of its host plant is co-located. Maps that show the potential of a northward expansion in the range of an agricultural pest (e.g. Fig. 2) obviously require that the agricultural crop can also expand northward. Based on soil and climatic suitability by 2100 , Ramankutty et al. (2002) predicted that northern Canada has 1.5 million $\mathrm{km}^{2}$ of land that could be developed into cropland. Furthermore, they showed that southern parts of the provinces of Canada are one of the most sensitive areas to changes in temperature (Ramankutty et al., 2002). Ramankutty et al.'s work shows the potential for more agriculture in the northern parts of Canada and less in southern Ontario, which could pose a problem if these northern climates are also suitable for crop pests. Moreover, Patterson et al. (1999) and others have suggested that climate change may reduce the efficacy of pesticides on target pests due to climatic instability and extreme weather events and may pose a challenge in controlling pest outbreaks.

Despite the potential for agriculture to shift northward, much of that potential applies to western Canada. Because of the Canadian Shield in the northern regions of Ontario and Quebec, the soil in these areas will probably never be suitable for agriculture, regardless of the climate. Thus, some of the northward 'expansion' of the range of swede midge would more likely represent a potential range contraction, as the expansion is toward land that is less suitable for crops. On the other hand, the westward shift in the swede midge's bioclimatic envelope encompasses land that is already currently in agricultural use for canola (Olfert et al., 2006); a crop readily attacked by the swede midge.

\section{Acknowledgements}

This work was supported in part by grants from the Canadian Natural Sciences and Engineering Research Council (NSERC) and the Ontario Ministry of Agriculture, Food and Rural Affairs (OMAFRA), University of Guelph Sustainable Production Program to Hallett and Newman. We thank the associate editor Hefin Jones, and two anonymous referees for their very helpful comments on an earlier version of this manuscript.

\section{References}

Allen RG, Pereira LS, Raes D, Smith M (1998) Crop evapotranspiration - guidelines for computing crop water requirements. FAO Irrigation and Drainage Paper 56.

Bale JS, Masters GJ, Hodkinson ID et al. (2002) Herbivory in global climate change research: direct effects of rising temperature on insect herbivores. Global Change Biology, 8, 1-16.

Beaumont LJ, Hughes L (2002) Potential changes in the distributions of latitudinally restricted Australian butterfly species in response to climate change. Global Change Biology, 8, 954-971.

Beaumont LJ, Pitman AJ, Poulsen M, Hughes L (2007) Where will species go? Incorporating new advances in climate modelling into projections of species distributions. Global Change Biology, 13, 1368-1385

Bonsal BR, Prowse TD, Pietroniro A (2003) An assessment of global climate model-simulated climate for the western cordillera of Canada (1961-90). Hydrological Processes, 17, 3703-3716.

Canadian Food Inspection Agency (2007) Swede Midge - Ontario 2007 Map. http:/ / www.inspection.gc.ca/english/sci/surv/ 2007maps/cnqzon2007e.shtml. CFIA Plant Health Division.

Coviella CE, Trumble JT (1999) Effects of elevated atmospheric carbon dioxide on insect-plant interactions. Conservation Biology, 13, 700-712.

Crozier L, Dwyer G (2006) Combining population-dynamic and ecophysiological models to predict climate-induced insect range shifts. The American Naturalist, 167, 853-866. 
del Barrio G, Harrison PA, Berry PM, Butt N, Sanjuan ME, Pearson RG, Dawson $T$ (2006) Integrating multiple modelling approaches to predict the potential impacts of climate change on species' distributions in contrasting regions: comparison and implications for policy. Environmental Science and Policy, 9, 129-147.

Dennis RLH, Hardy PB (1999) Targeting squares for survey: predicting species richness and incidence of species for a butterfly atlas. Global Ecology and Biogeography, 8, 443-454.

ESRI (2005) ARCGIS. 9.1, Environmental Systems Research Institute Inc., Canada.

Estrada-Pena A (2002) Increasing habitat suitability in the United States for the tick that transmits Lyme disease: a remote sensing approach. Environmental Health Perspectives, 110, 635-640.

Eyre MD, Rushton SP, Luff ML, Telfer MG (2004) Predicting the distribution of ground beetle species (Coleoptera, Carabidae) in Britain using land cover variables. Journal of Environmental Management, 72, 163-174.

Gavin DG, Hu FS (2006) Spatial variation of climatic and nonclimatic controls on species distribution: the range limit of Tsuga heterophylla. Journal of Biogeography, 33, 1384-1396.

Gevrey M, Worner SP (2006) Prediction of global distribution of insect pest species in relation to climate by using an ecological informatics method. Journal of Economic Entomology, 99, 979-986.

Hallett RH, Heal JD (2001) First Nearctic record of the swede midge (Diptera: Cecidomyiidae), a pest of cruciferous crops from Europe. The Canadian Entomologist, 133, 713-715.

Hampe A (2004) Bioclimate envelope models: what they detect and what they hide. Global Ecology and Biogeography, 13, 469-471.

Harrison PA, Berry PM, Butt N, New M (2006) Modelling climate change impacts on species' distributions at the European scale: implications for conservation policy. Environmental Science $\mathcal{E}$ Policy, 9, 116-128.

Hill JK, Thomas CD, Huntley B (1999) Climate and habitat availability determine 20th century changes in a butterfly's range margin. Proceedings of the Royal Society B: Biological Sciences, 266, 1197-1206.

IPCC (2001) The scientific basis: Projections of Future Climate Change. Climate Change 2001: IPCC Third Assessment Report, pp. 527-582.

IPCC (2002) The IPCC Data Distribution Centre. http://tinyurl. com/2uetzd. Accessed 1 February 2007.

IPCC (2007) Chapter 8: Climate Models and their Evaluation. Climate Change 2007: IPCC Fourth Assessment Report, pp. 589-662.

Lindgren E, Talleklint L, Polfeldt T (2000) Impact of climatic change on the northern latitude limit and population density of the disease-transmitting European tick Ixodes ricinus. Environmental Health Perspectives, 108, 119-123.

Luoto M, Poyry J, Heikkinen RK, Saarinen K (2005) Uncertainty of bioclimate envelope models based on the geographical distribution of species. Global Ecology and Biogeography, 14, 575-584.

McKenney DW, Hopkin AA, Campbell KL, Mackey BG, Foottit R (2003) Opportunities for improved risk assessments of exotic species in Canada using bioclimatic modeling. Environmental Monitoring and Assessment, 88, 445-461.

Nakicenovic N, Alcamo J, Davis Get al. (2000) Special Report on Emissions Scenarios: A Special Report of Working Group III of the Intergovernmental Panel on Climate Change, pp. 1-599, Cambridge University Press, Cambridge, UK.

New M, Hulme M, Jones PD (1999) Representing twentieth century space-time climate variability. Part 1: development of a 1961-90 mean monthly terrestrial climatology. Journal of Climate, 12, 829-856.

Newman JA (2004) Climate change and cereal aphids: the relative effects of increasing $\mathrm{CO}_{2}$ and temperature on aphid population dynamics. Global Change Biology, 10, 5-15.

Newman JA (2005) Climate change and the fate of cereal aphids in southern Britain. Global Change Biology, 11, 940-944.

Newman JA (2006) Using the output from global circulation models to predict changes in the distribution and abundance of cereal aphids in Canada: a mechanistic modeling approach. Global Change Biology, 12, 1634-1642.

Oberhauser K, Peterson AT (2003) Modeling current and future potential wintering distributions of eastern North American monarch butterflies. Proceedings of the National Academy of Sciences of the United States of America, 100, 14063-14068.

Olfert O, Hallett R, Weiss RM, Soroka J, Goodfellow S (2006) Potential distribution and relative abundance of swede midge, Contarinia nasturtii, an invasive pest in Canada. Entomologia Experimentalis et Applicata, 120, 221-228.

Olfert O, Weiss RM, Woods S, Philip H, Dosdall L (2004) Potential distribution and relative abundance of an invasive cereal crop pest, Oulema melanopus (Coleoptera: Chrysomelidae), in Canada. The Canadian Entomologist, 136, 277-287.

Patterson DT, Westbrook JK, Joyce RJV, Lingren PD, Rogasik J (1999) Weeds, Insects, and Diseases. Climatic Change, 43, 711-727.

Pearson RG, Dawson TP (2003) Predicting the impacts of climate change on the distribution of species: are bioclimate envelope models useful? Global Ecology and Biogeography, 12, 361-371.

Pearson RG, Dawson TP, Berry PM, Harrison PA (2002) SPECIES: a spatial evaluation of climate impact on the envelope of species. Ecological Modelling, 154, 289-300.

Pearson RG, Thuiller W, Araujo MB et al. (2006) Model-based uncertainty in species range prediction. Journal of Biogeography, 33, 1704-1711.

Ramankutty N, Foley JA, Norman J, McSweeney K (2002) The global distribution of cultivable lands: current patterns and sensitivity to possible climate change. Global Ecology and Biogeography, 11, 377-392.

Readshaw JL (1961) The biology and ecology of the swede midge, Contarinia nasturtii (Keiffer) (Diptera, Cecidomyiidae). Doctoral thesis, University of Durham, Durham, UK.

Readshaw JL (1966) The ecology of the swede midge, Contarinia nasturtii (Keiffer) (Diptera, Cecidomyiidae): I. Life-history and influence of temperature and moisture on development. Bulletin of Entomological Research, 56, 685-700.

Robertson MP, Villet MH, Palmer AR (2004) A fuzzy classification technique for predicting species' distributions: applications using invasive alien plants and indigenous insects. Diversity \& Distributions, 10, 461-474. 
Segurado P, Araujo MB (2004) An evaluation of methods for modelling species distributions. Journal of Biogeography, 31, $1555-1568$.

Stokes BM (1953) The host plant range of the swede midge (Contarinia nasturtii Kieffer) with special reference to types of plant damage. European Journal of Plant Pathology, 59, 82-90.

Sutherst RW, Maywald GF, Bottomley W, Bourne A (2004) CLIMEX Version 2 User's Guide. Hearne Scientific Software Pty Ltd, Melbourne, Vic., Australia.

Sutherst RW, Maywald GF, Russell BL (2000) Estimating vulnerability under global change: modular modelling of pests. Agriculture, Ecosystems and Environment, 82, 303-319.

Terblanche JS, Klok CJ, Krafsur ES, Chown SL (2006) Phenotypic plasticity and geographic variation in thermal tolerance and water loss of the tsetse Glossina pallidipes (Diptera: Glossinidae): implications for distribution modelling. The American Journal of Tropical Medicine and Hygiene, 74, 786-794.
Thomas CD, Cameron A, Green RE et al. (2004) Extinction risk from climate change. Nature, 427, 145-148.

Thuiller W (2004) Patterns and uncertainties of species' range shifts under climate change. Global Change Biology, 10, 20202027.

Thuiller W, Lavorel S, Araujo MB (2005) Niche properties and geographical extent as predictors of species sensitivity to climate change. Global Ecology and Biogeography, 14, 347-357.

United States Department of Agriculture (2007) Animal and Plant Health Inspection Service: Swede Midge. http:/ / tinyurl. com/2sh28h. Accessed 3 May 2007.

Wilkinson PR (1967) The distribution of Dermacentor ticks in Canada in relation to bioclimatic zones. Canadian Journal of Zoology, 45, 517-537.

Xu D, Yan H (2001) A study of the impacts of climate change on the geographic distribution of Pinus koraiensis in China. Environment International, 27, 201-205. 